
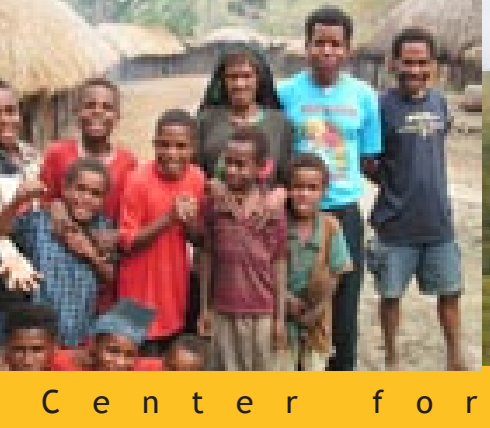

Forests and
Governance Programme

\title{
Kopermas: Masyarakat Hukum Adat sebagai Tameng bagi Pihak yang Berkepentingan
}

\begin{abstract}
Asih Yulianti
Kegiatan penebangan kayu yang izin penebangannya dikeluarkan oleh Pemerintah Daerah (Pemda) Kabupaten Manokwari, Papua, yang lebih dikenal dengan Kopermas (Koperasi Peranserta Masyarakat Adat), belum berdampak pada Masyarakat Hukum Adat (MHA) pemilik Kopermas. Hal ini terjadi karena sebagian besar MHA memiliki pengetahuan yang sangat rendah tentang koperasi, keuangan dan kehutanan. Pemda diharapkan dapat membantu meningkatkan pengetahuan MHA, dalam berorganisasi dalam koperasi, merencanakan dan mengelola keuangan, kegiatan eksploitasi hutan yang berazas kelestarian serta jenis kayu yang bernilai komersial dan nilai jualnya. Hanya demikian tujuan Kopermas, yaitu membangun dan menumbuhkan pemberdayaan perekonomian MHA di dalam maupun di sekitar hutan, dapat tercapai.
\end{abstract}

\section{Kopermas di Kabupaten Manokwari}

Antara tahun 2000 - 2003, Pemda Kabupaten Manokwari menerbitkan 84 izin Kopermas. Pada akhir tahun, dua Kopermas masih produktif sedangkan 82 Kopermas macet (produktif dalam waktu singkat). Keadaan ini menimbulkan beberapa pertanyaan. Apakah faktor penyebab Kopermas produktif atau macet? Apakah Kopermas yang masih produktif dapat membangun dan menumbuhkan pemberdayaan perekonomian MHA di dalam maupun di sekitar hutan? Ataukah sebaliknya?

\section{Tiga Tahun Keberlangsungan Kopermas Kaironi}

Tahun 2000, atas nama MHA yang bertempat di Kampung Kasi, beberapa orang pendiri berpendidikan tinggi (berasal dari personal aparat pemerintah dan swasta) membentuk Kopermas Kaironi. Untuk melengkapi kelembagaan Kopermas, maka diambil enam orang anggota MHA sebagai pengurus Kopermas Kaironi. Kebanyakan pengurus Kopermas Kaironi tidak tamat SLTP bahkan ada yang tidak tamat SD dan tidak mempunyai pengetahuan tentang koperasi, kehutanan dan keuangan. Selebihnya, diambil 22 orang tenaga kerja dari luar anggota MHA untuk membantu menjalankan kegiatan Kopermas Kaironi.

Modal awal Kopermas Kaironi berasal dari kompensasi yang dibayarkan oleh mitra kerja (PT. TAIWI), senilai Rp. 50.000.000. Dengan modal ini, Kopermas Kaironi mulai menjalankan usahanya. Tahun 2001, Kopermas Kaironi melakukan kegiatan penebangan dan pengapalan, bekerja sama dengan PT. TAIWI. Kegiatan eksploitasi dilakukan sepenuhnya oleh PT. TAIWI. Dalam tahun 2001 - 2003, volume kayu yang dihasilkan sebesar 32.367,62 $\mathrm{m}^{3}$. Penetapan harga jual berdasarkan hasil kesepakatan Kopermas Kaironi dan PT. TAIWI adalah Rp. $50.000,-/ \mathrm{m}^{3}$, untuk semua jenis kayu. Nilai ini dibagi, untuk biaya operasional Kopermas senilai Rp. 10.000 sampai dengan Rp. 10.500 dan untuk MHA senilai Rp. 39.500 sampai dengan Rp. 40.000 . 
Tabel 1. Hasil Penjualan Kayu Log oleh Kopermas Kaironi

\begin{tabular}{rrrrr}
\hline Tahun & $\begin{array}{c}\text { Volume } \\
\left(\mathrm{m}^{3}\right)\end{array}$ & $\begin{array}{c}\text { Total } \\
\text { Penerimaan (Rp) }\end{array}$ & $\begin{array}{c}\text { Penerimaan } \\
\text { Masyarakat (Rp) }\end{array}$ & \multicolumn{1}{c}{$\begin{array}{c}\text { Penerimaan } \\
\text { Kopermas (Rp) }\end{array}$} \\
\hline 2001 & 3.000 & 150.000 .000 & 120.000 .000 & 30.000 .000 \\
\hline 2002 & $23.641,89$ & 1.182 .094 .500 & 939.335 .575 & 242.788 .925 \\
\hline 2003 & $5.725,73$ & 286.286 .500 & 174.634 .765 & 60.120 .165 \\
\hline Total & $32.367,62$ & 1.618 .381 .000 & 1.233 .970 .340 & 332.909 .090 \\
\hline
\end{tabular}

Hasil penjualan kayu log oleh Kopermas Kaironi digunakan untuk kegiatan operasional Kopermas, yaitu: administrasi, upah tenaga kerja, sewa log pond dan kesejahteraan masyarakat. Pengeluaran biaya dilakukan setelah adanya penerimaan dari hasil penjualan kayu. Cash flow Kopermas Kaironi dapat dilihat pada tabel 1.

Tabel 2 menunjukkan bahwa manfaat yang diperoleh tidak dapat menutupi biaya yang dikeluarkan. Terlihat secara finansial, Kopermas Kaironi tidak layak dilanjutkan karena mengalami kerugian. Hal ini terjadi karena biaya administrasi pada tahun 2000 dan 2001 melebihi manfaat. Biaya ini lebih banyak dikeluarkan untuk mengurus dokumen usaha, baik di Kabupaten maupun Propinsi. Terlihat manfaat tahun 2000 senilai 98\% dari biaya dan tahun 2001 senilai 23\% dari biaya. Tahun 2002 dan 2003, manfaat lebih besar dari biaya, tetapi karena tahun 2000 dan 2001 terjadi negatif pada kas maka manfaat tahun 2002 dan 2003 di gunakan untuk mempositifkan kas. Ternyata kas tidak terjadi positif karena negatif pada tahun 2000 dan 2001 lebih besar dari positif tahun 2002 dan 2003.

\section{Mengapa Kopermas Kaironi masih terus berjalan, padahal secara finansial mengalami kerugian?}

Dalam menjalankan usaha, Kopermas Kaironi berkoordinasi dengan berbagai pihak, yaitu Pemerintah Kabupaten, Dinas Kehutanan, TNI/ POLRI, mitra kerja (PT. TAIWI) dan masyarakat. Koordinasi dilakukan agar kegiatan Kopermas tetap berjalan dan produk yang dihasilkan dapat terjual. Di balik koordinasi ternyata semua pihak mempunyai kepentingan yang sama, yaitu mendapatkan keuntungan. Penerimaan tidak sepenuhnya diterima oleh Kopermas Kaironi dan MHA karena sebagian diserahkan kepada pihak lain guna kelancaran produksi. Biaya pergaulan ini, yang sebagian besar dikeluarkan guna kelancaran pengapalan, tahun 2001 mencapai 72\%. Tahun 2002 mencapai 74\% dan tahun 2003 mencapai 76\%. Walaupun kas Kopermas Kaironi bernilai negatif, tetapi masih bisa mengeluarkan biaya, karena didanai oleh PT. TAIWI.

Tabel 2. Cash Flow Kopermas Kaironi (Dengan, $i=12,54 \%$ )

\begin{tabular}{|c|c|c|c|c|}
\hline \multirow{2}{*}{ Activity (Kegiatan) } & \multicolumn{4}{|c|}{ Year (Tahun) } \\
\hline & 2000 (Rp) & 2001 (Rp) & 2002 (Rp) & 2003 (Rp) \\
\hline \multicolumn{5}{|l|}{ Benefit (Manfaat) } \\
\hline 1. Modal awal & 50.000 .000 & - & - & - \\
\hline 2. Hasil penjualan kayu & - & 30.000 .000 & 242.788 .925 & 60.120 .165 \\
\hline Total Benefit & 50.000 .000 & 30.000 .000 & 242.788 .925 & 60.120 .165 \\
\hline
\end{tabular}

\begin{tabular}{lcrrr}
\hline Cost (Biaya) & & & \\
\hline 1. Administrasi & 51.100 .000 & 97.150 .000 & 15.618 .440 & 2.500 .000 \\
\hline 2. Upah tenaga kerja & - & 22.490 .000 & 186.930 .000 & 47.980 .000 \\
\hline 3. Sewa log pond & - & 2.000 .000 & 16.000 .000 & 4.000 .000 \\
\hline 4. Lain-lain & - & 9.500 .000 & 6.750 .000 & - \\
\hline Total Cost & 51.100 .000 & 131.140 .000 & 225.298 .440 & 54.480 .000 \\
\hline & & & & \\
\hline Net Benefit (Cost) & & & & \\
\hline Net Value of Net Benefit Cost) & & & & \\
\hline
\end{tabular}

Hasil pada baris ${ }^{1 /}$ diperoleh dari total benefit - total cost Hasil pada baris ${ }^{2 /}$ diperoleh dari hasil pada baris $1 /:(1+i)^{t}$ 


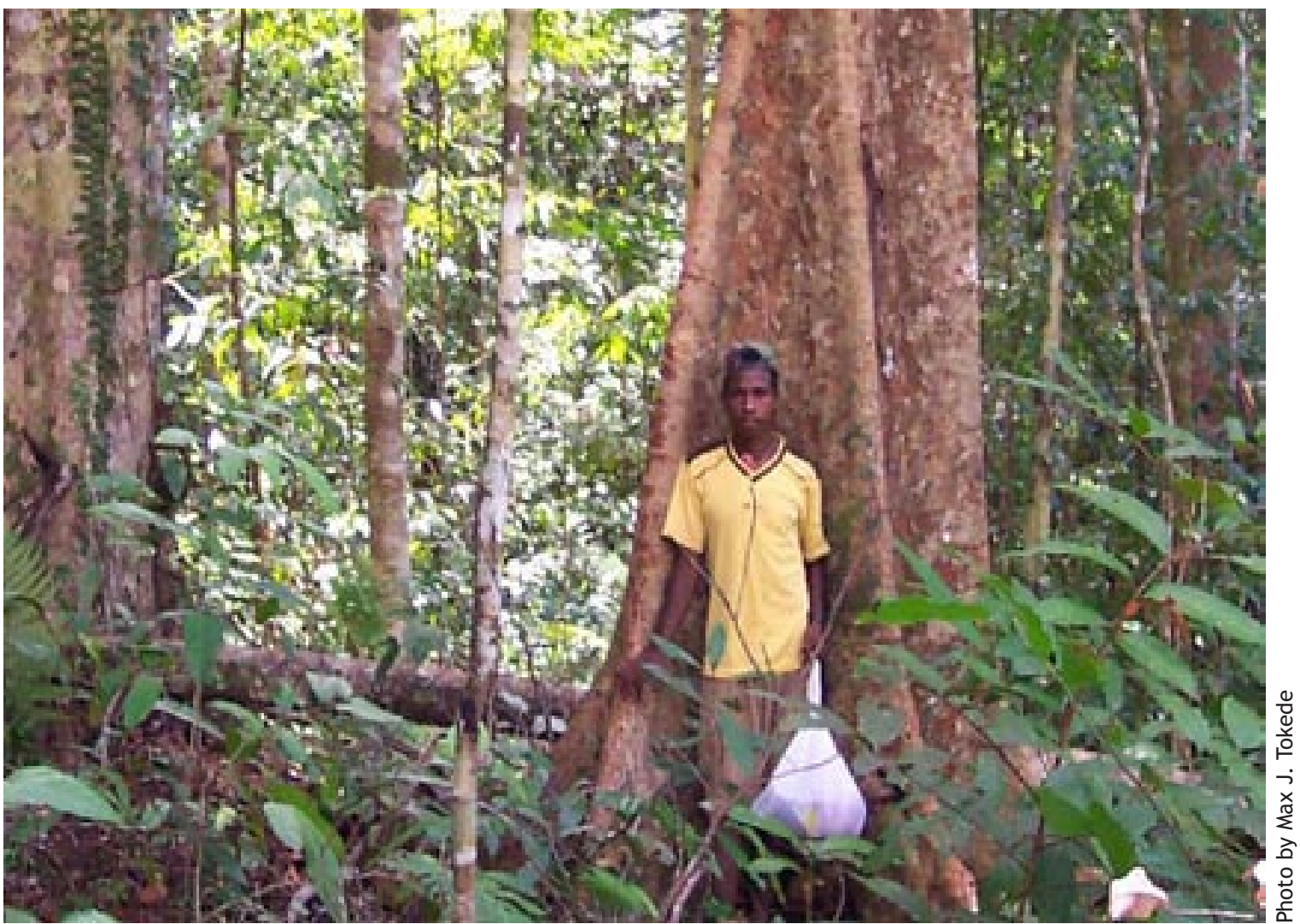

Keuntungan hasil penjualan kayu yang diberikan Kopermas Kaironi kepada MHA pun, hanya diserahkan pada Kepala Suku. Selanjutnya pembagian keuntungan bagi MHA, sepenuhnya berada di tangan Kepala Suku. Akibatnya Kepala Suku yang mendapat keuntungan terbesar. MHA yang seharusnya menerima manfaat dari Kopermas Kaironi, hanya merasakan manfaat dan menikmati keuntungan dalam jangka waktu pendek, bahkan hanya sesaat.

Akibatnya, keadaan perekonomian MHA yang seharusnya lebih baik setelah adanya Kopermas, masih menjadi impian. MHA hanya menjadi tameng oleh pihak yang berkepentingan untuk mencari keuntungan.

\section{Kesimpulan}

1. Tujuan Kopermas Kaironi tidak tercapai karena MHA pemilik Kopermas adalah kelompok yang paling sedikit menikmati manfaat dan keuntungan Kopermas. Manfaat dan Keuntungan Kopermas Kaironi sebagian besar dinikmati oleh pengusaha, personal aparat pemerintah dan swasta.

2. Sumber daya manusia MHA tidak mendukung dan belum siap dijadikan pengelola sumber daya hutan dalam skala besar, yang dilakukan secara cepat dan komersil. Akibatnya MHA yang seharusnya menjadi pemain dalam usaha Kopermas Kaironi, hanya sebagai penonton. Hal ini membuat kelompok elit yang memiliki kemampuan, meraih manfaat dan keuntungan besar dari Kopermas Kaironi.

\section{Rekomendasi}

1. Karena usaha yang dilakukan selama ini tidak meningkatkan perekonomian MHA, izin usaha penebangan kayu oleh Kopermas Kaironi sebaiknya dihentikan dan diganti dengan jenis usaha lain, seperti pemanfaatan hasil hutan bukan kayu (Sagu, Bambu, Pandan dan Melinjo).

2. Agar bisa mandiri dalam mengelola sumber daya hutan dan dapat menikmati manfaat langsung untuk perbaikan perekonomian, MHA sebaiknya memenuhi beberapa persyaratan sebelum memperoleh izin eksploitasi hutan. Persyaratan ini agar termuat dalam petunjuk pelaksanaan hak pemungutan hasil hutan MHA pada areal hutan produksi, dan meliputi juga persyaratan kemampuan berorganisasi dalam koperasi, merencanakan dan mengelola keuangan, kegiatan eksploitasi hutan yang berazas kelestarian serta tata niaga kayu. Untuk itu dibutuhkan pula dukungan pelatihan dan penyuluhan. 
3. Kebijakan Pemda agar dibuat berdasarkan keadaan di lapangan termasuk pola pengelolaan hutan tiap daerah. Selama ini kebijakan pemerintah terarah pada usaha penebangan kayu sedangkan masyarakat yang bergantung pada hutan lebih mengandalkan hasil hutan bukan kayu. Yang dibutuhkan adalah kebijakan yang lebih mementingkan MHA, dalam hal ini perlindungan terhadap usaha pemanfaatan hasil hutan bukan kayu oleh MHA.

Governance Brief ini ditulis dalam rangka partisipasi penulis dalam program "Building Leadership for Forest Reforms of the Future" yang diselenggarakan atas kerjasama CIFOR dan Ford Foundation Jakarta dan merupakan ringkasan thesis Sarjana Kehutanan (S1) Universitas Negeri Papua, 2004 dengan judul "Analisis Biaya Usaha Kopermas Kaironi di Distrik Masni Kabupaten Monokwari".

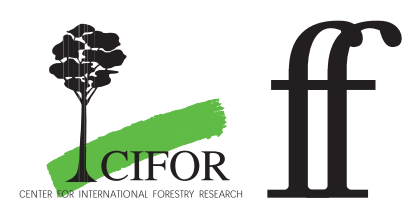

Center for International Forestry Research, CIFOR Alamat kantor: Jalan CIFOR, Situ Gede, Sindang Barang Bogor Barat 16680, Indonesia.

Alamat surat: P.O. Box. 6596 JKPWB, Jakarta 10065 Indonesia
Tel: +62(251) 622622 Fax: +62(251) 622100

E-mail: cifor@cgiar.org

Website: www.cifor.cgiar.org

Foto sampul oleh: Douglas Sheil dan Miriam Van Heist

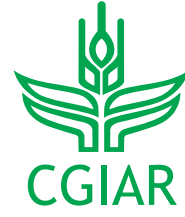

$F \cup T U R E$ HAR Y/E S T

Program Forests and Governance di CIFOR mengkaji cara pengambilan dan pelaksanaan keputusan berkenaan dengan hutan dan masyarakat yang hidupnya bergantung dari hutan. Tujuannya adalah meningkatkan peran serta dan pemberdayaan kelompok masyarakat yang kurang berdaya, meningkatkan tanggung jawab dan transparansi pembuat keputusan dan kelompok yang lebih berdaya dan mendukung proses-proses yang demokratis dan inklusif yang meningkatkan keterwakilan dan pengambilan keputusan yang adil di antara semua pihak. 